\title{
Práticas avaliativas inovadoras na universidade: pressupostos epistemológicos e metodológicos no Curso de Letras da UEFS.
}

\author{
Mylena Jannis de Oliveira Santos ${ }^{1}$; Marinalva Lopes Ribeiro ${ }^{2}$ \\ 1. Bolsista PIBIC/CNPq, Graduanda em Licenciatura em Letras Vernáculas, Universidade Estadual de Feira de \\ Santana, e-mail: mylena.jannis@gmail.com \\ 2. Orientadora, Departamento de Educação, Universidade Estadual de Feira de Santana, e-mail: \\ marinalva_biodanza@hotmail.com
}

PALAVRAS-CHAVE: Ensino Superior; Avaliação da aprendizagem; Práticas inovadoras.

\section{INTRODUÇÃO}

Este trabalho apresenta alguns resultados do plano de trabalho: Práticas avaliativas inovadoras na universidade: pressupostos epistemológicos e metodológicos no Curso de Letras da UEFS, realizado no período de agosto/2017 a julho/2018.

A prática de avaliar a aprendizagem está associada ao (in)sucesso dos sujeitos em processo de desenvolvimento, cuja a responsabilidade cabe ao professor, portanto é um tema relevante para discussão na universidade.

O trabalho objetivou conhecer a base epistemológica e metodológica da avaliação de professores Curso de Licenciatura em Letras, destacando em um dos objetivos específicos as concepções de avaliação quem têm professores e estudantes de Letras.

Apresentamos, em síntese, os métodos utilizados, os resultados e discussão e, por fim, as considerações finais.

\section{METODOLOGIA}

A pesquisa realizada, de natureza qualitativa, oportunizou a percepção aprofundada das concepções sobre avaliação da aprendizagem de duas professoras e 18 estudantes do Curso de Letras Vernáculas da UEFS, por meio de narrativas viabilizadas mediante entrevistas semiestruturadas e um questionário.

Os dados produzidos no estudo foram analisados com base no método Análise de conteúdo (BARDIN, 2009). Por questões éticas, os sujeitos foram identificados com nomes fictícios ou as iniciais EL, seguido de um algarismo que representa a ordem numérica dos estudantes.

\section{RESULTADOS E/OU DISCUSSÃO (ou Análise e discussão dos resultados)}

Inicialmente, apresentamos os resultados e análise dos dados produzidos pelos estudantes e, em seguida, aqueles produzidos pelas professoras que participaram da pesquisa.

Os dados produzidos pelos estudantes foram organizados em cinco categorias as quais se desdobraram em algumas subcategorias, entretanto neste trabalho apresentaremos apenas duas. Com relação aos professores, os dados foram compostos em nove dimensões, das quais serão abordadas somente duas. Em relação aos estudantes destacamos as seguintes tendências:

\section{Tendência tradicional da avaliação da aprendizagem}


Fica explícito nas narrativas dos estudantes, que a avaliação é um processo em que o professor obtém resultados através de exames e provas e a partir destes instrumentos ele mede o conhecimento adquirido pelos discentes, com a finalidade de averiguar o que foi aprendido durante um período. Vejamos as narrativas a seguir:

Avaliação voltada para a preparação de exames, pois os sistemas de ensino atualmente estão interessados nos percentuais de aprovação e reprovação dos alunos. Com isso, os procedimentos de avaliação se tornam elementos motivadores em busca de resultados (EL6).

Um processo complexo que afere o conhecimento adquirido por uma pessoa, normalmente utilizando como instrumento para alcançar tal finalidade a tradicional "prova (EL7).

A avaliação da aprendizagem para mim é um método de verificar o que se aprende durante um período [...] (EL12).

\title{
2. Tendência construtivista da avaliação da aprendizagem
}

Apesar dos posicionamentos apresentados anteriormente sobre avaliação, encontramos em nossa pesquisa estudantes que já ultrapassaram essa visão, a exemplo do discente EL8, como observarmos a seguir:

\begin{abstract}
Avaliação da aprendizagem para mim vai além de uma prova, não deve ser levado em consideração apenas o conhecimento aplicado naquela folha de papel, mas sim todo o desenvolvimento do aluno durante o processo de aprendizagem. Uma avaliação da aprendizagem é feita com a interação do aluno com a disciplina, e a dinâmica é muito diferente com a que se está acostumado (EL8).
\end{abstract}

Na narrativa de EL8, a avaliação da aprendizagem é vista como um processo que vai "além de uma prova". Desta maneira, o docente deve considerar, não só o que o estudante expõe no momento da aplicação da avaliação, mas também todo o percurso do desenvolvimento formativo, ou seja, todo o seu crescimento ou retrocesso, visto que a vida acadêmica perpassa por diversas alternâncias, sendo possível que o aluno possa vivenciar alguma situação que o impeça de progredir na aprendizagem, o que deve ser conhecido e levado em consideração pelo professor, descaracterizando o que Freire (1983) designa como "Educação Bancária", no qual o objetivo é o acúmulo de conhecimento.

\section{Sentidos atribuídos à avaliação pelas docentes}

Quanto aos docentes, sujeitos deste estudo, notamos dois posicionamentos diferenciados: enquanto uma professora concebe a avaliação como um exame final, a outra a concebe como um processo que contribui para a aprendizagem dos educandos.

Segundo a narrativa da professora Nívea, a avaliação da aprendizagem é:

[...] um momento em que vamos checar se todo aquele trabalho que estamos fazendo, se está surtindo um efeito [...]. O professor vai ver se o trabalho desenvolvido por ele tá surtindo efeito e o aluno vê o trabalho que ele está tendo a estudar, ao se dedicar àquela disciplina, ao curso que tá fazendo, se ele está conseguindo atingir aos seus objetivos e aos objetivos do curso. É um momento de ambas as partes verem, analisarem, observarem se o que estão fazendo valeu, né? Se vale a pena, se está indo bem, se está atingindo os objetivos, se tá dando resultado pra que possa prosseguir, verificar se precisa e o que é que precisa ser mudado, né? aprimorado, transformado (Nívea). 
Desta maneira, para a docente Nívea, a avaliação da aprendizagem não é apenas um momento único da prática, mas um processo em que durante seu desenvolvimento os sujeitos envolvidos passam a observar quais etapas foram alcançadas ou não. A partir dos resultados os professores traçam novas estratégias para as próximas etapas do que foi ideado.

Desta forma, é perceptível que a docente utiliza a avaliação da aprendizagem como uma oportunidade de melhoria para a formação profissional e a realização pessoal dos estudantes, tornando-a, segundo Luckesi (2000, p. 3), um "[...] ato dinâmico, que implica na decisão de 'o que fazer'. Sem este ato de decidir, o ato de avaliar não se completa".

Já para a docente Fernanda, a avaliação da aprendizagem apresenta outro sentido, como podemos observar a seguir:

Eu acho que avaliação da aprendizagem é um processo complexo, difícil, e que vem mudando ao longo dos anos de acordo com as nossas noções de educação. [...] não existe avaliação sem que o professor tenha um objetivo a ser alcançado, se ele não tiver isso em mente, ele não tem o que avaliar. Ele vai avaliar somente as tarefas, e avaliar tarefas não é o nosso papel, mas avaliar além das tarefas (Fernanda).

É perceptível a relevância dada pela docente em estabelecer os objetivos da avaliação da aprendizagem para a prática docente, os quais guiarão sua trajetória para o semestre em curso, entretanto, não fica explícito quais objetivos são propostos à aprendizagem. Destaca-se, também, que a avaliação para a professora Fernanda está ligada à ideia de complexidade, dificuldade, com a qual concordamos. Diante disso, torna-se viável o desenvolvimento profissional dos professores universitários para dirimir as dificuldades em relação a essa etapa da prática docente.

\section{CONSIDERAÇÕES FINAIS}

Ao analisar os sentidos atribuídos à avaliação sob a visão dos estudantes do Curso de Letras Vernáculas e das professoras Fernanda e Nívea concluímos que, apesar do debate intenso acerca da necessidade de mudança de paradigma e postura docente nas universidades, observamos que alguns dos sujeitos deste estudo ainda se mantêm atrelados ao Paradigma Tradicional/Conservador, a exemplo da docente Fernanda e de alguns estudantes que participaram da pesquisa, pois a avaliação sob seus olhares é um momento estanque, apenas de verificação e obtenção de notas.

Em contrapartida, é notório que para a professora Nívea e outros discentes, a avaliação da aprendizagem é vista como um momento para fomentar a reflexão e o redirecionamento da prática docente, para superar as dificuldades dos educandos, fazendo com que eles reconheçam os pontos fracos e fortes, a fim de avançarem na aprendizagem, desta forma, podemos inferir que tais sujeitos possuem tendências amparadas no Paradigma Construtivista/Emergente.

\section{REFERÊNCIAS}

BARDIN, L. Análise do Conteúdo. Lisboa: Edições 70, 2009.

FREIRE, Paulo. EDUCAÇÃO E MUDANÇA. 7. ed. Rio de Janeiro: Paz e Terra, 1983. 
LUCKESI, Cipriano Carlos. O que é mesmo o ato de avaliar? In: Revista Pátio - Ano 3 $-\mathrm{N}^{\mathrm{o}} 12$ - fevereiro/abril 2000. 